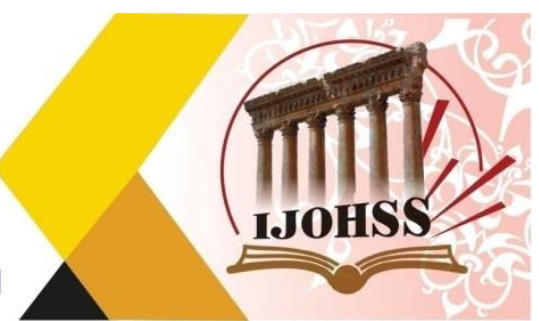

\title{
اللجان النيابية و اثرها في العملية التشريعية ــ اشارات للحالة العراقية العملة
}

م. عمر سعد خالا

كلية المنصور الجامعة

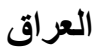

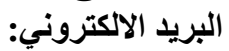

omer.khalid@muc.edu.iq

\author{
م. علي محمد حسن الخفاجي \\ كلية القانون - جامعة القادية القفية

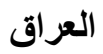

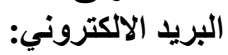 \\ ali.mohammad@qu.edu.iq
}

الملخص المبرن

إن البرلمان او المجلس النيابي هو السلطة الوحيدة في النظام السياسي التي تجمع بين مهمتين رئيسيتين هما الانابة

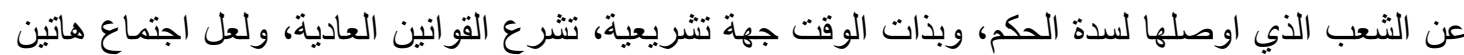

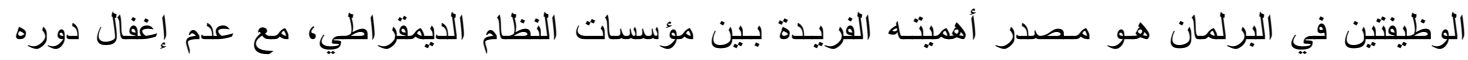

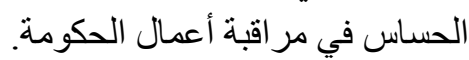

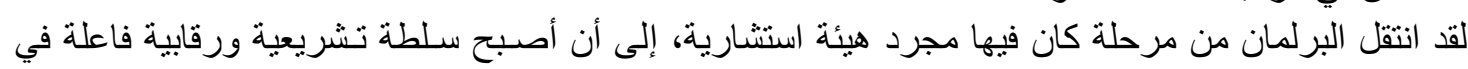

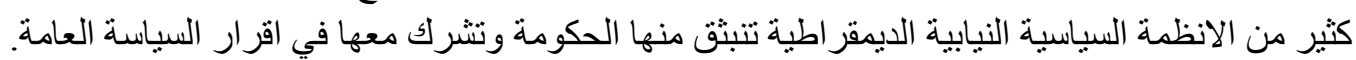

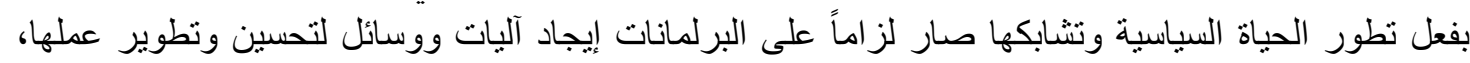

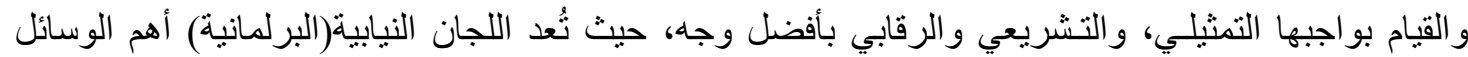

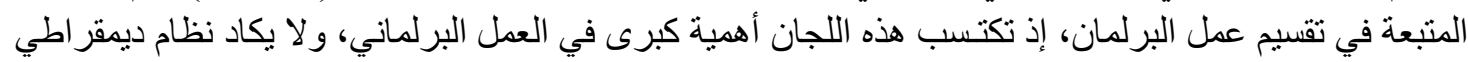

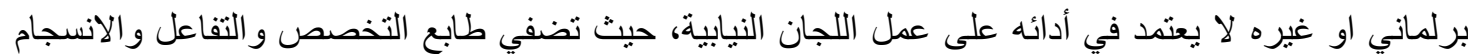
بين اعضائه.

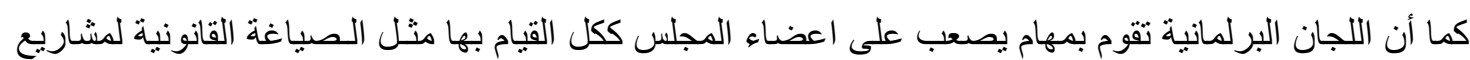

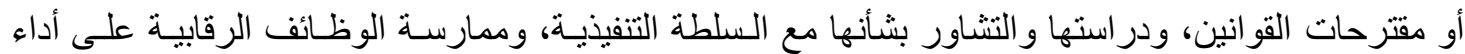

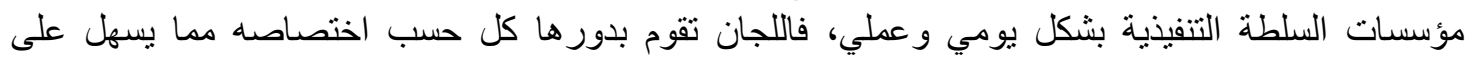
البرلمان اداء مهامه بشكل في تشريع وتعديل القو انين، او الرقابة على أعمال السلطات الاخرى. الكلمات المفتاحية: المجلس النيابي، البرلمان، مشروع القانون، المجالس النيابية (البرلمانية). 


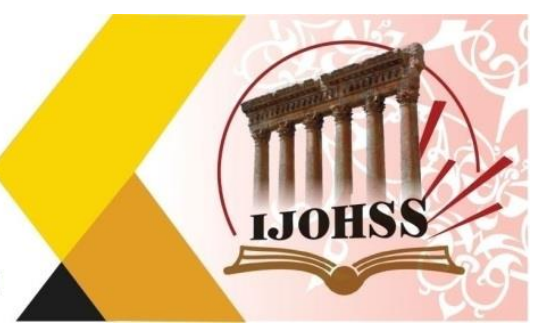

\title{
Parliamentary Committees and their Role in Proposing and Legislating Regular Laws in Iraq
}

\author{
Lect. Ali Muhammad Hassan Al-Khafaji \\ College of Law - University of Al- \\ Qadisiyah \\ Iraq \\ Email: ali.mohammad@qu.edu.iq
}

\author{
Lect. Omar Saad Khaled \\ Al-Mansour University College \\ Iraq \\ Email: omer.khalid@muc.edu.iq
}

\begin{abstract}
Parliament or the Representative Council is the only authority in the political system that combines two main tasks, which are proxy for the people who brought it to power, and at the same time a legislative body that legislates regular laws, and perhaps the meeting of these two functions in Parliament is the source of its unique importance among the institutions of the democratic system, with Not to lose sight of his sensitive role in monitoring government actions.
\end{abstract}

Parliament has moved from a stage in which it was merely an advisory body, to becoming an effective legislative and oversight authority in many democratic parliamentary political systems from which the government emerges and participates with it in adopting a public policy. Due to the development of political life and its intertwining, it became imperative for parliaments to find mechanisms and means to improve and develop their work, and to carry out their representative, legislative and oversight duty in the best way, as parliamentary committees are the most important means used in the division of parliament's work, as parliamentary committees gain great importance in parliamentary work, and there is hardly a system A parliamentary democrat or any other person who does not depend in his performance on the work of parliamentary committees, as it gives the character of specialization, interaction and harmony among its members.

Parliamentary committees carry out tasks that are difficult for members of the Council as a whole to perform, such as the legal drafting of draft laws or proposals of laws, studying and consulting about them with the executive authority, and exercising oversight functions over the performance of the institutions of the executive authority on a daily and practical basis. The committees perform their role each according to their competence, which makes it easier for Parliament. Performing his duties in a way in legislating and amending laws, or monitoring the work of other authorities.

Keywords: Parliament, proposing laws, draft law and parliamentary committees. 
اصبحت الديمقر اطية هدفاً تحاول بلو غه الدول شتى واهم سمة من سمات الدولة الحديثة ومظهر من مظاهر ها اذ اذ الدئ

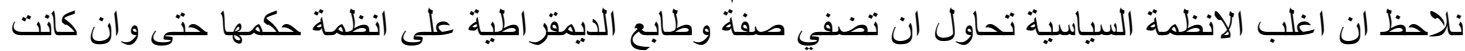

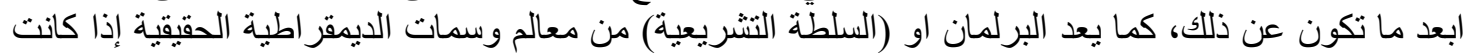

طريقة تكونه عبر الاقتراع الحر الدوري وفي البرلئ دستور دائم، ما يعني تمثيل الار ادة الثعبية لأغلبية المواطنين.

إن البرلمان هو السلطة الاساسية من سلطات الدول الثناث التي تمثل الثعب بشكل غير مباشر عن طريق الوكالة

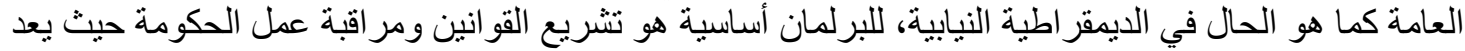

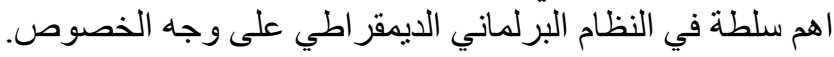

و عليه تعتمد البرلمانات في أداء وظيفتها الرقابية و التشريعية على اللجان البرلمانية وبصورة أساسية على اللجان

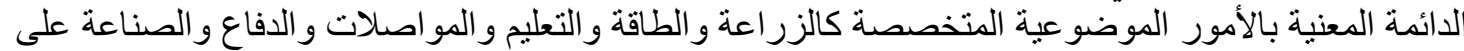

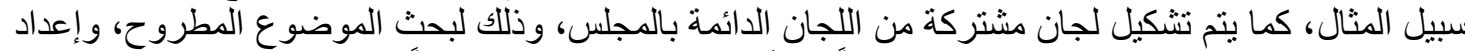

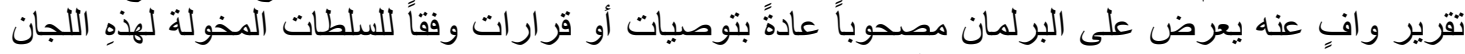

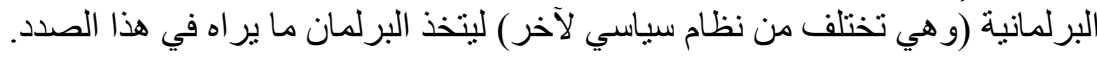

من ناحية أخرى، قد يقوم البرلمان بتشكيل لجان تحقيق خاصة ومؤقتتة، للوقوف على متابعة الأداء الحكومي إزاء

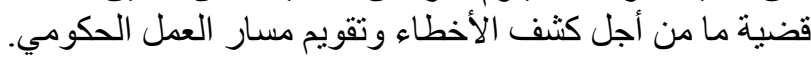

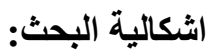

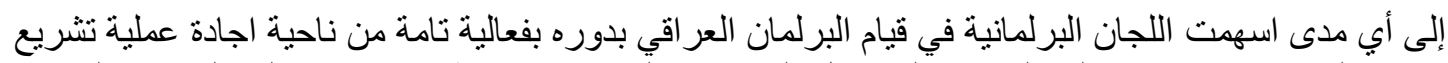

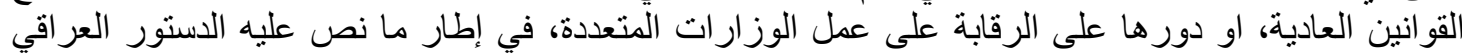
الدائم و النظام الداخلي لمجلس النواب.

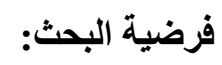

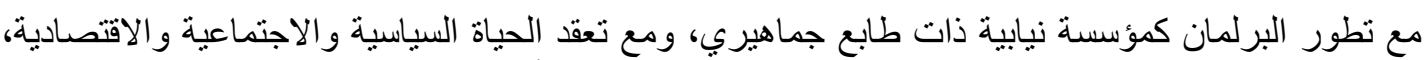

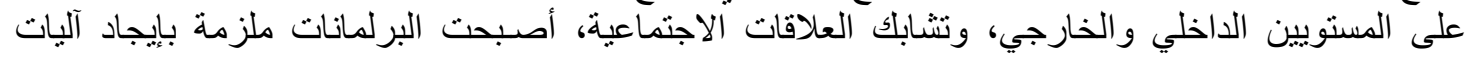

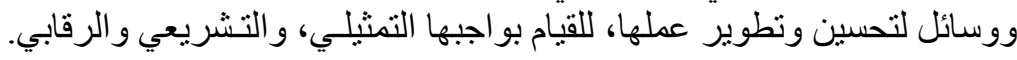

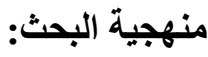

اتبعنه في بحثا هذا عدة مناهج منها المنهج التاريخي لتتبع مراحل نشوء اللجان البرلمانية في العهود السياسية

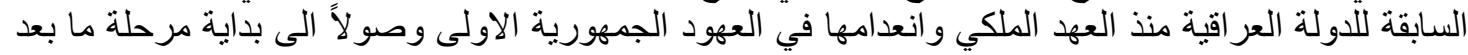

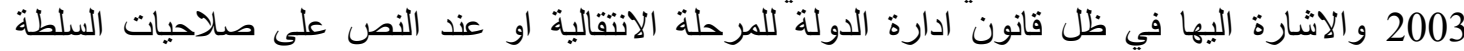

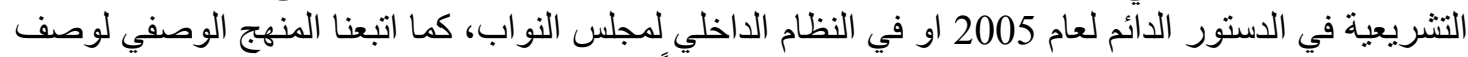

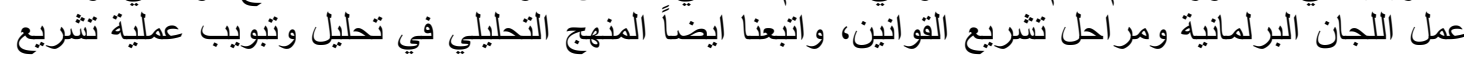

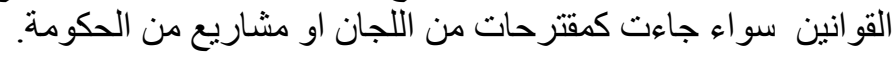

هيكلية البحث:

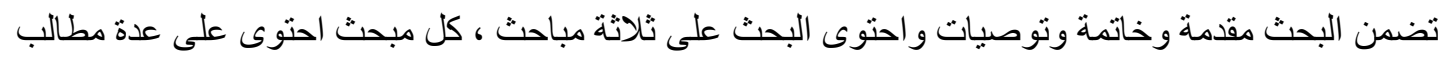

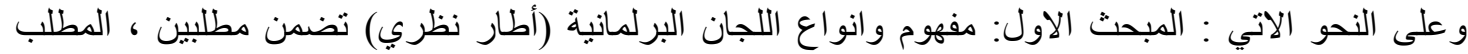

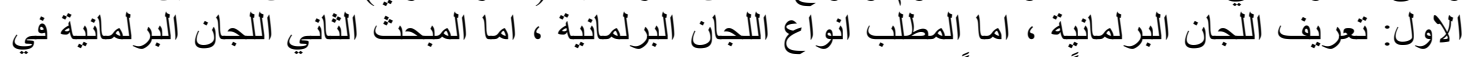

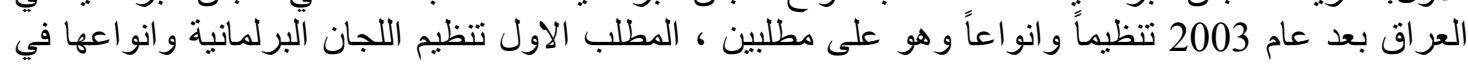


قانون ادارة الدولة العر اقية للمرحلة الانتقالية ، اما المطلب الثاني هو تنظيم اللجان البرلمانية و انوانو اعها في الدستور

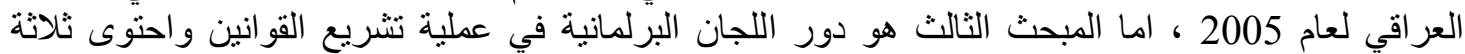

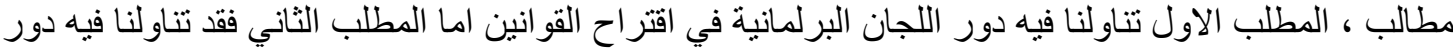

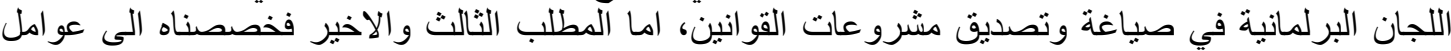
نجاح اللجان البرلمانية في العملية التشريعية .

المبحث الاول: مفهوم وانواع اللجان النيابية (أطار نظري)

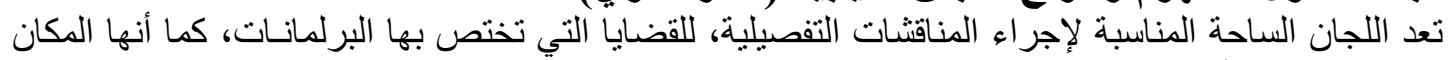

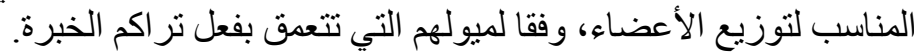

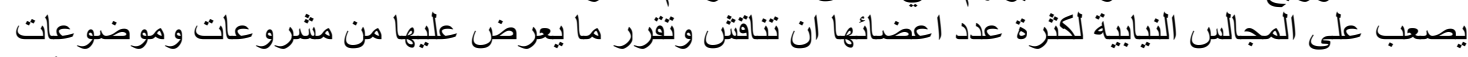

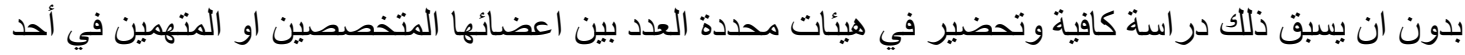

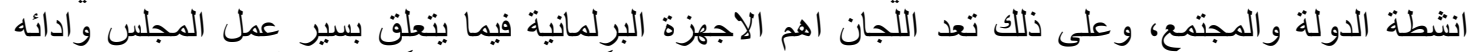

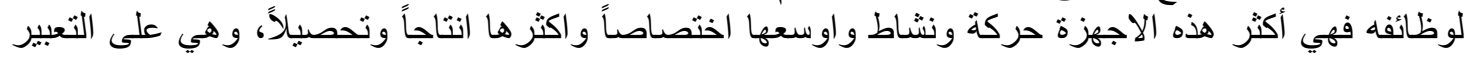
الدارج الذي يغذي كل اعمال المجلس. وبالتالي يستلزم التّعريف باللجان البرلمانية التئ، ونتكيلها وكيفية فحص الموضو عات داخل تلك اللجان و على النحو الآتي:

المطلب الاول: تعريف اللجان النيابية:

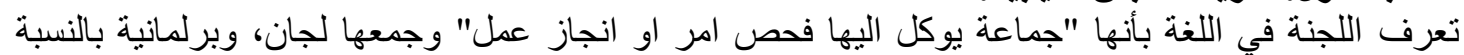

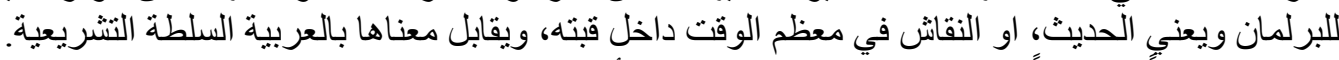

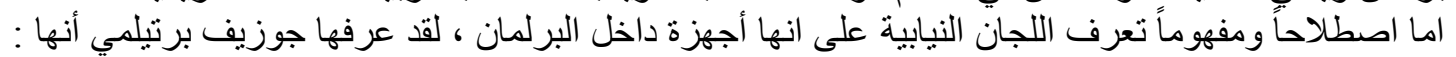

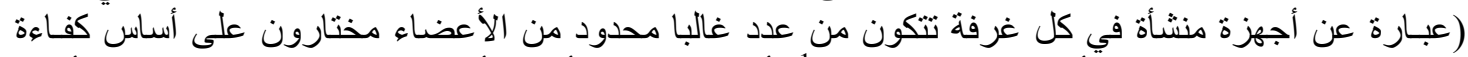

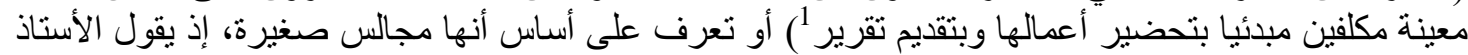

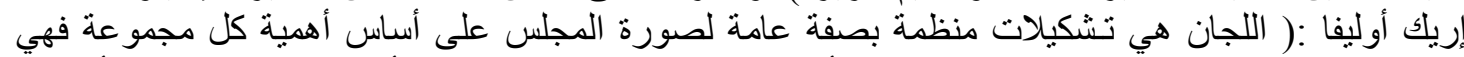

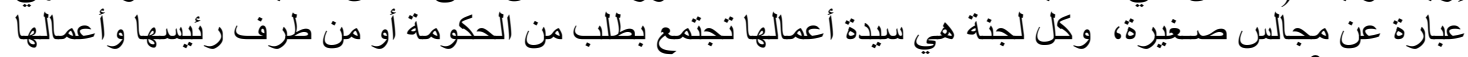

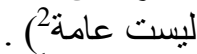
ويمكن أيضاً تعريف اللجان النيابية بأنها "اجهزة يشكله البرلمان او المجلس النيابي للحصول على رأي جماعات

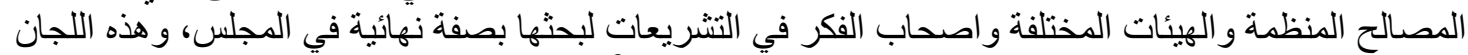

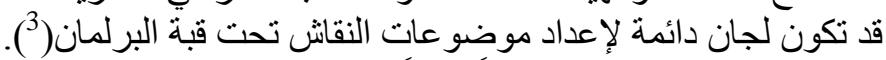

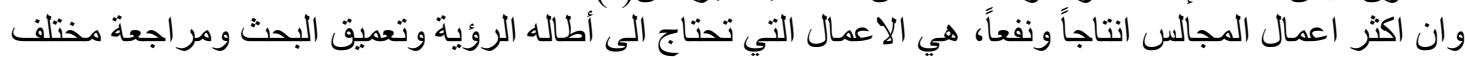

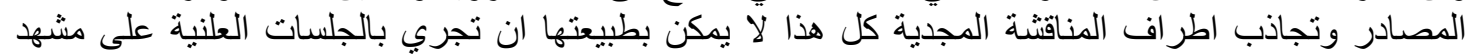

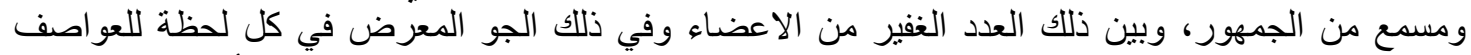

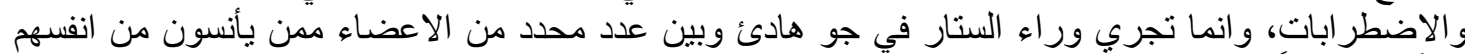

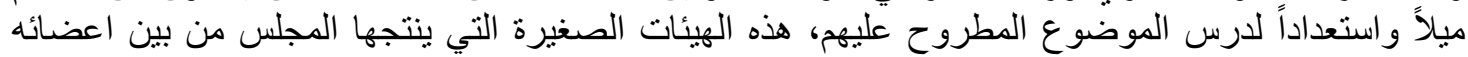

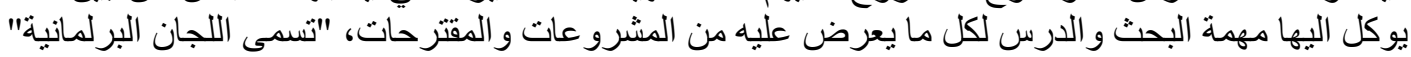

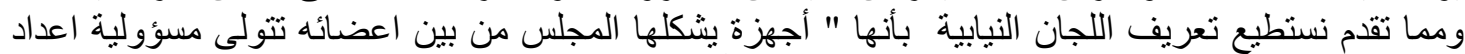

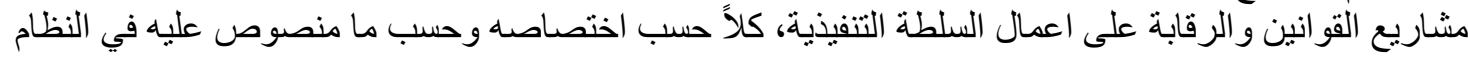

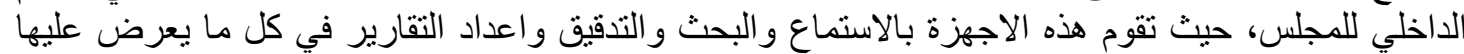

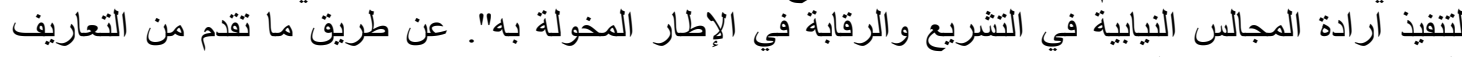

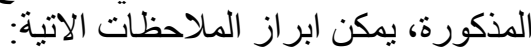
أولاً: مبدأ التخصيص: يرنكز نظام الملام اللجان البرلمانية على مبدأ ذائع الانتشار والقبول هو مبدأ تقسيم وتوزيع

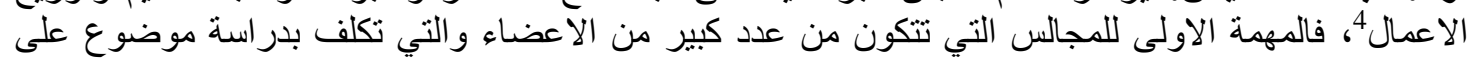


درجة من التداخل و التشعب هو تكليف بعض اعضائها بعمل در اسة مبدئية لهذا الموضوع وتجميع وترتيب كافة

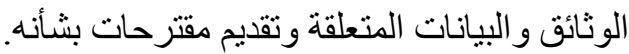

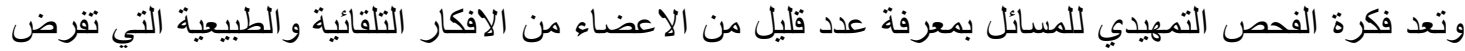

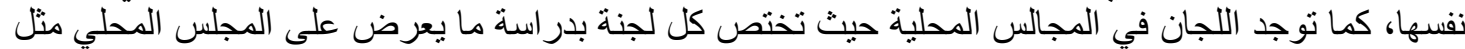

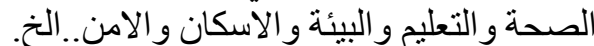

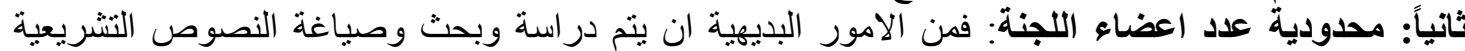

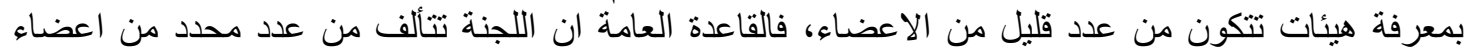

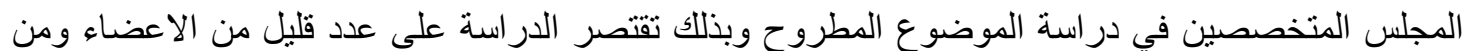

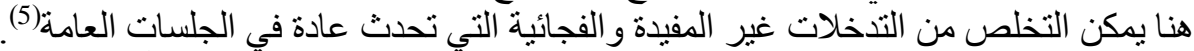

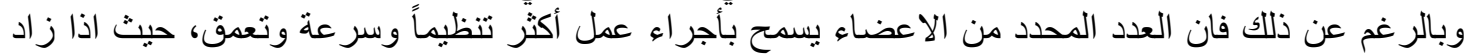

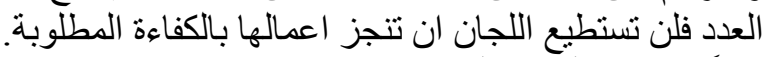

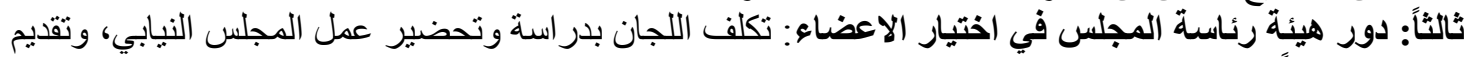

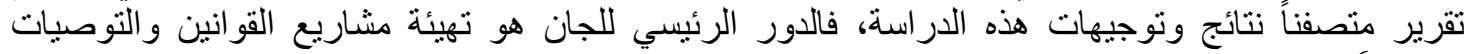

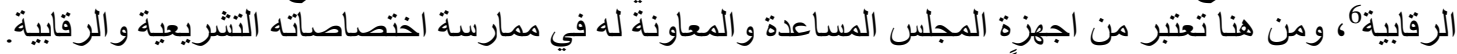

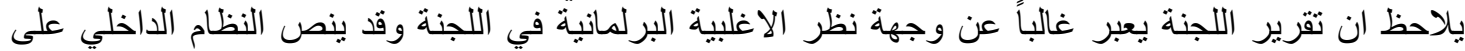

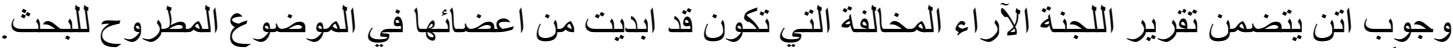

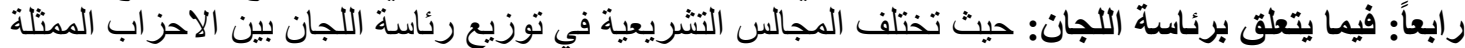

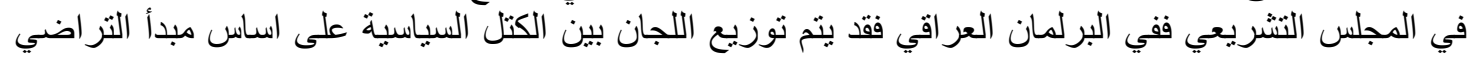

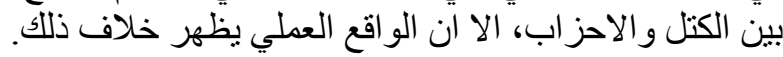

المطلب الثاني: انواع اللجان النيابية:

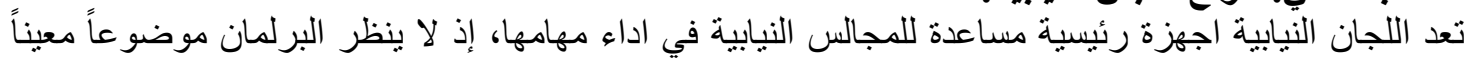

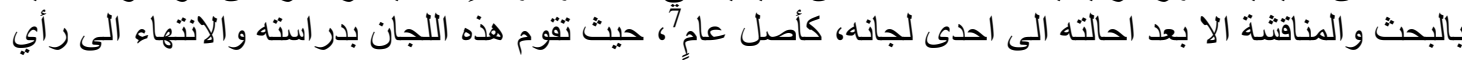

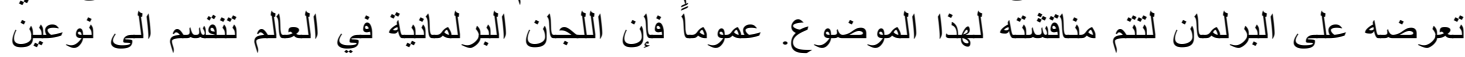
رئيسيين: النوع الأول: وتشمل اللجان الدائمة المتخصصة او النوعية التي تختص بدراسة ما يعرض على على المجلس من أنس

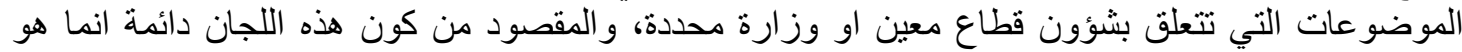

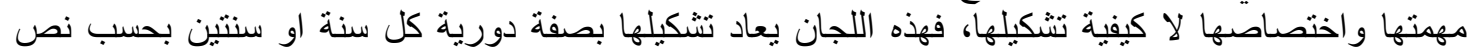
اللائحة الداخلية لكل مجلس نيابي، فإن هذه اللجان لان تستمد وجودها من قرار مؤقة فئت يصدر من رئاسة المجلس

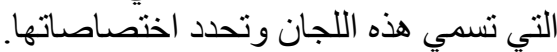

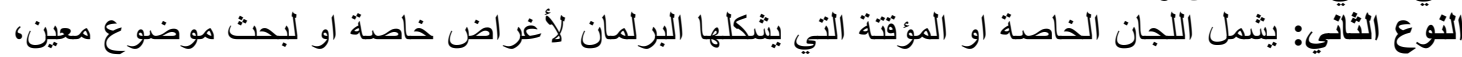

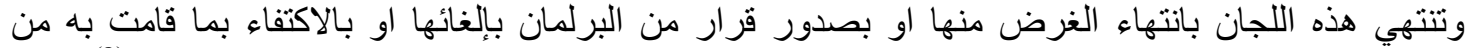

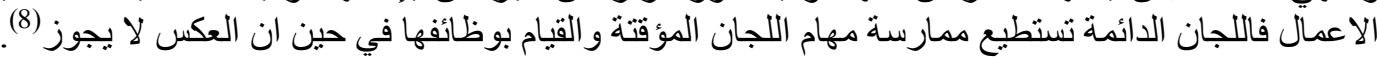

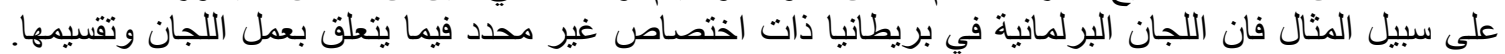

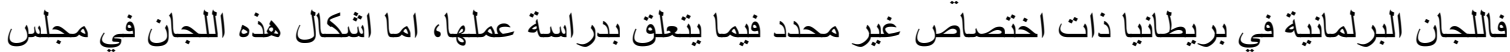

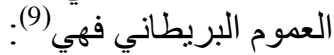

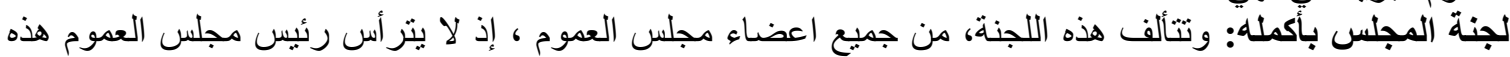

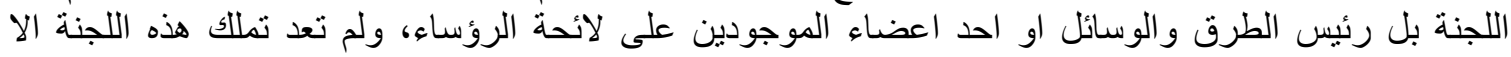

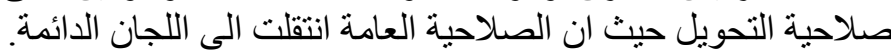

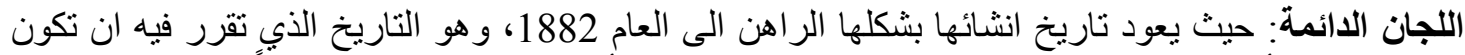

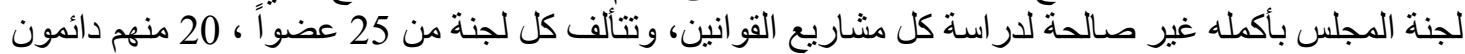

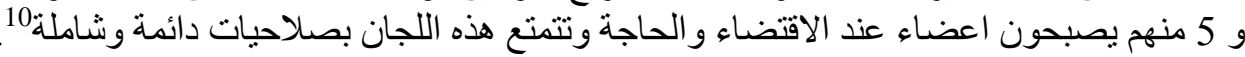




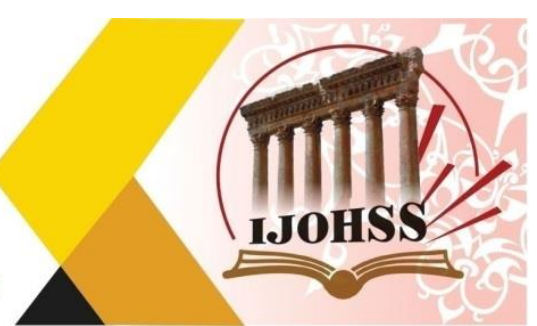

اما اللجان المختارة: وهي لجان خاصة تعين لدراسة مشروع قانونٍ لله خصوصية تقنية او للقيام بالتحقيق، اما

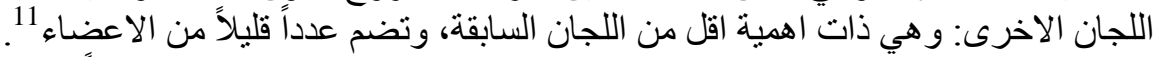

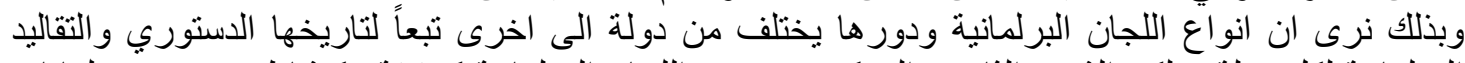

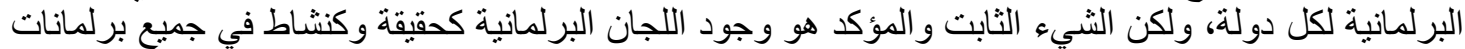
دول العالم، والاختلاف يكون فقط في التكوين و الدور ذه الذي يمكن ان تلعبه في عمل المجالس البرلمانات.

مخطط رقم (1) يوضح العملية التثريعية و دور اللجان النيابية .

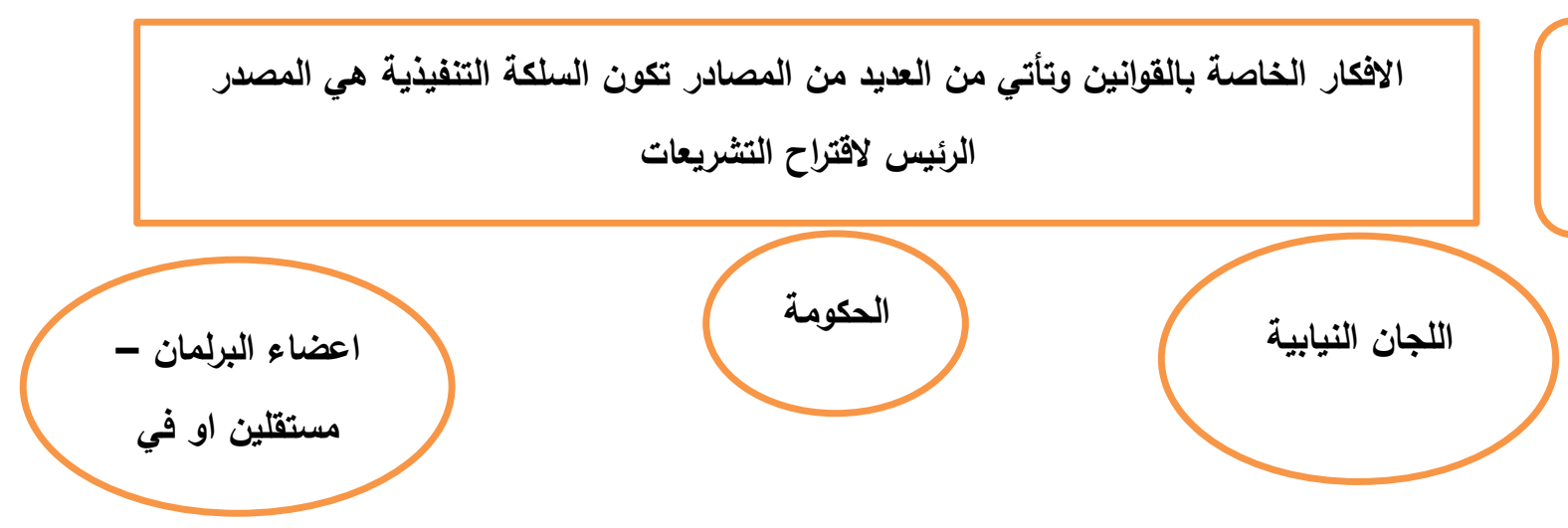

المصدر

قبل طرح القانون على البرلمان يتم عادة التثاور حول المبادئ العامة المتضمنة في القانون ، وقث يكون هناك اجراء رقابي قبل عملية التشريع تقوم به لجان البرلمان او جهات اخرى .

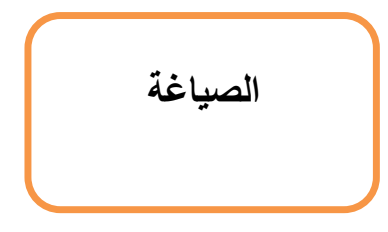

صياغة التشريع ن وهي عملية فنية تحتاج الى خبراء مختصين بالقانون وهم اما اعضاء البرلمان من اللجان القانونية و الخبراء الاستثاريون الذي يستعين بهم المجلس لأداء هذه المهام .

مجرد عرض مشروع القانون تقوم معظم البرلمانات بأجراء مناقثة علنية على المبدأ الذي يسعى مشروع القانون لتحقيقه وذلك قبل النظر في احكامه وصياغته ، وفي حال لم يتم اعتماده بالأغلبية المطلوبة عادتاً ما يترك المقترح دون المضي فيه 


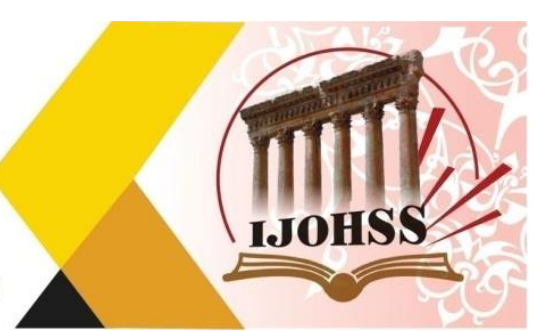

الدراسة المفصلة للنص وهذه المرحلة غالباً ما تكون الاكثر تعقيداً وهي مرحة متباينة من برلمان لأخر ، حيث يتم دراسة النص بشكل مفصل ويتم اجراء التعديلات عليه ، ويكون التعديل على عاتق اللجان البرلمانية المختصة بذلك التشريع.

يتوجب الموافقة على النص النهائي للمشروع في البرلمانات التي تعمل بنظام المجلسين بالأغلبية لكلا المجلسين

مجلس النواب
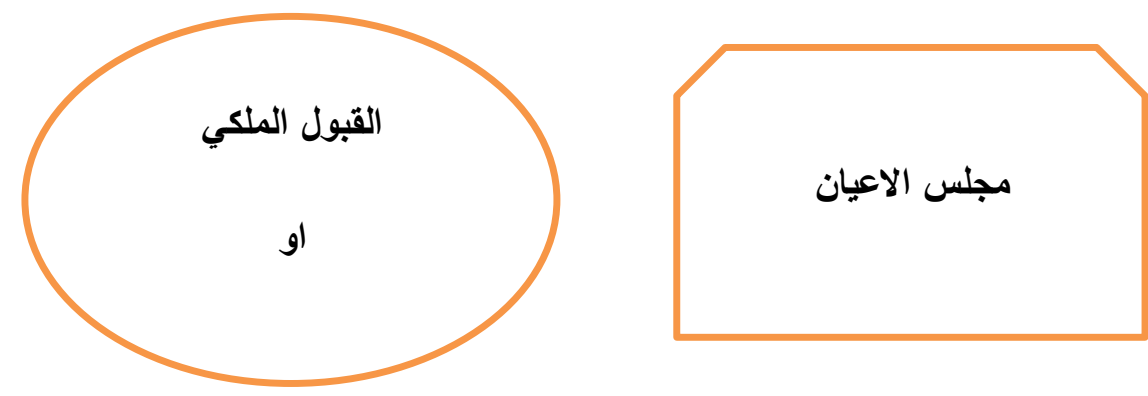

لا ينتهي كل شي بالضرورة لمجرد مناقشة التشريع من قبل اعضاء البرلمان ، حيث توجد العديد من عمليات المراجعة بعد التشريع والتي تتراوح بين المراجعة غير الرسمية ممن قبل اللجان البرلمانية لتحديد ما اذا كان التشريع يجري تطبيقه بشكل صحيح ويحقى النتائج المطلوية ، فضلاً عن المراجعات القضائية والقانونية(الطعن بالقانون) والتي قد تؤدي الى اسقاط القانون في حال لم يتوافق مع الدستور والاحكام القضائية الاخرى، او ما يسمى الرقابة على دستورية القوانين ·

Global ) المخطط من اعداد الباحث بالاستناد الى ورقة بحثية مقدمة من قبل معهد دليل عمل البرلمانات 
المطلب الاول: تنظيم اللجان النيابية وانواعها في قانون ادارة الدولة العراقية للمرحلة الانتقالية

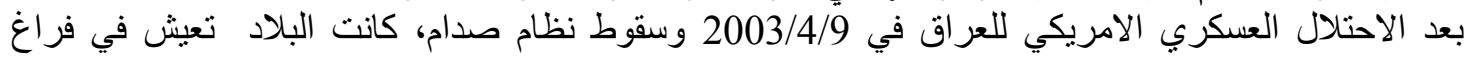

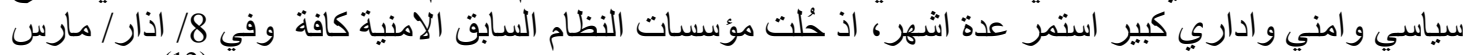

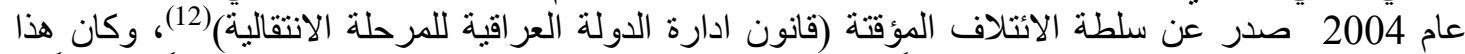

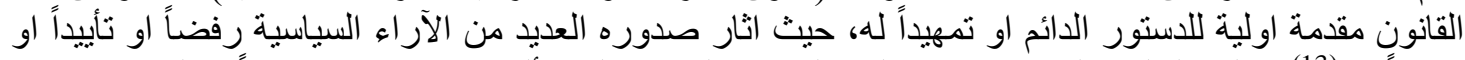

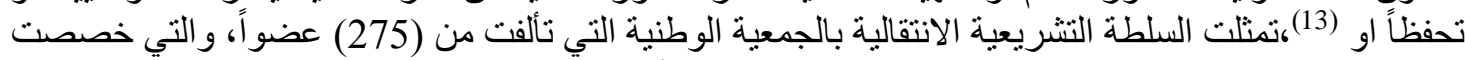

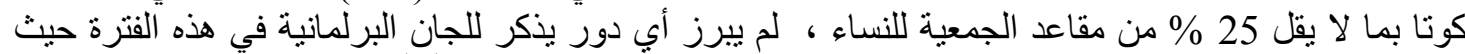

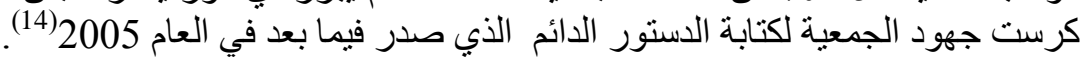

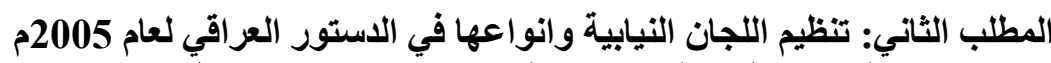

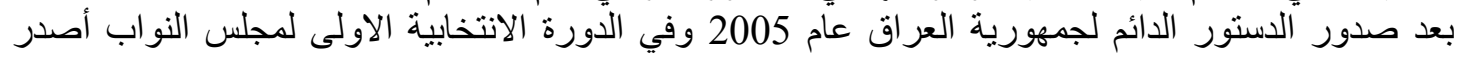

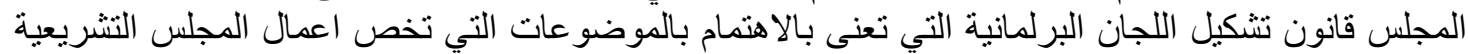

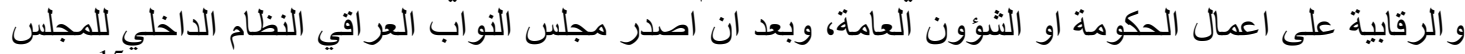

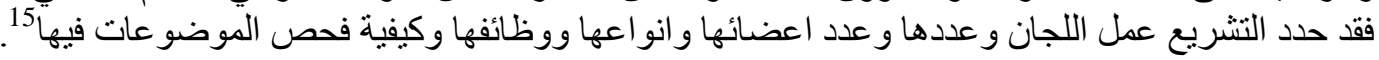

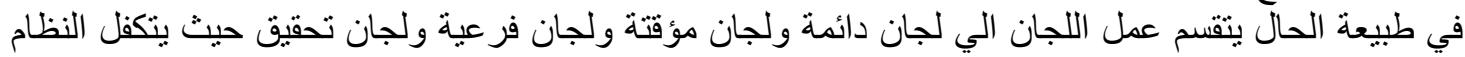

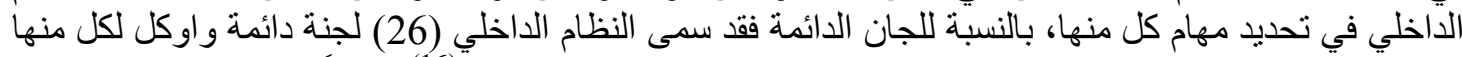

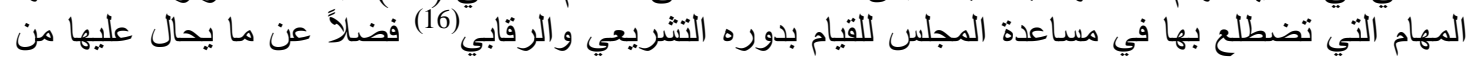
رئيس المجلس من الاقتراحات في مشروعات القواتئ انين المقدمة من عشرة من اعضاء مجلس النواب لدراستها

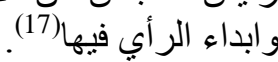

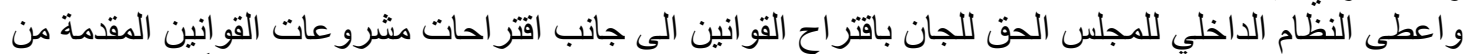

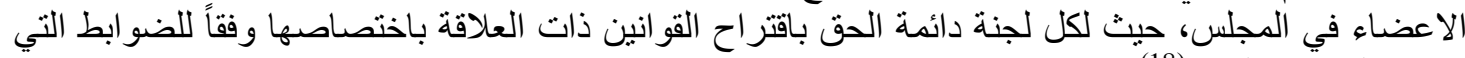

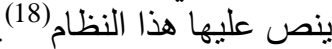
واضافة للجان الدائمة فأن للمجلس تشكيل لجان فرعية ولجان مؤقتة ولجان تحقيق بحسب مقتضيات العمل

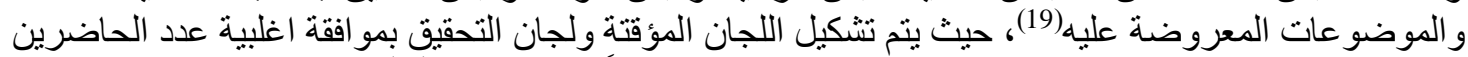

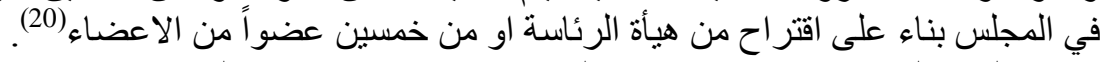

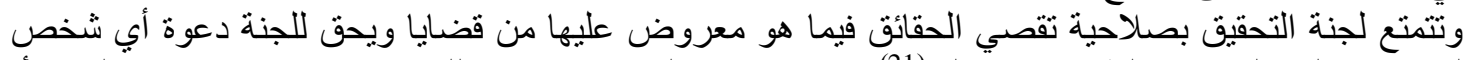

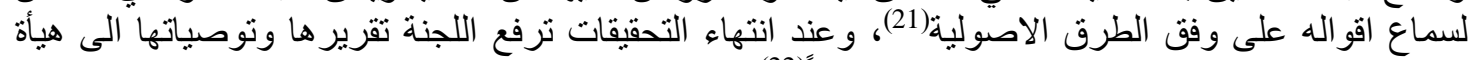

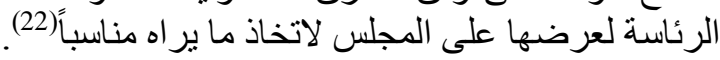

المبحث الثالث: دور اللجان النيابية في عملية تثريع القوانين

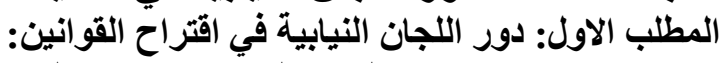

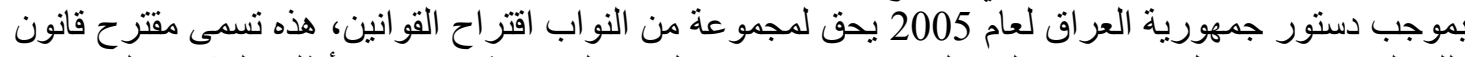

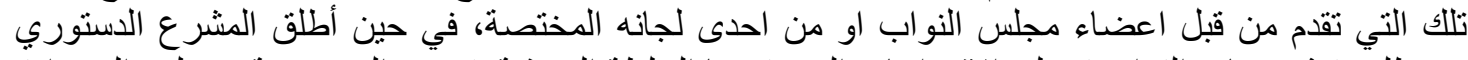

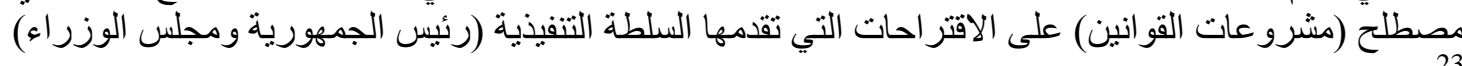

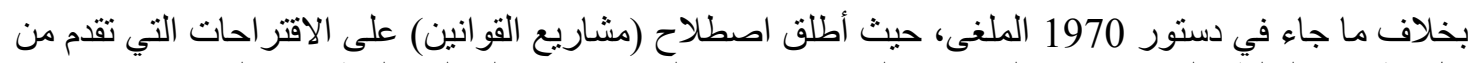

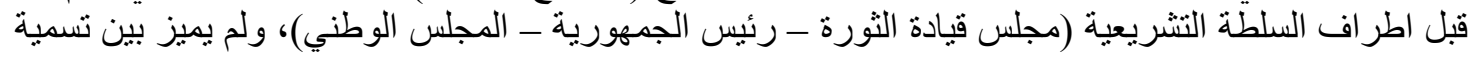

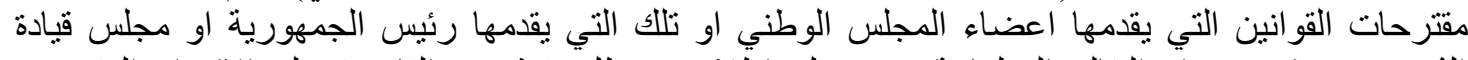

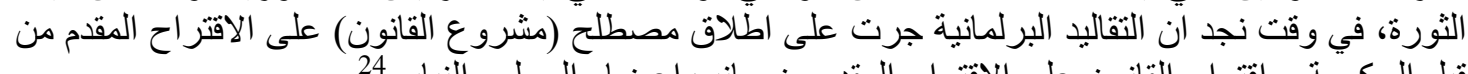

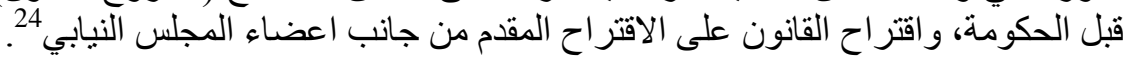


وقد اخذ قانون ادارة الدولة العراقية للمرحلة الانتقالية بنفس السياق، حيث اطلق اصطلاح (مشاريع القوانين) على الحئ

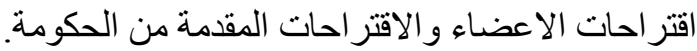

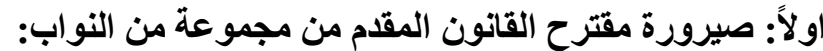

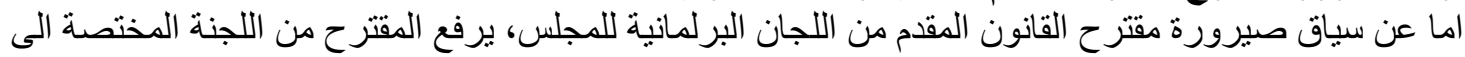

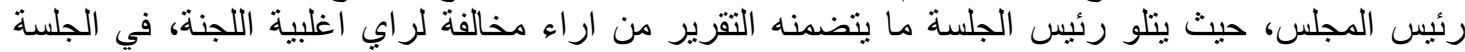
المخصصة للمناقشة.

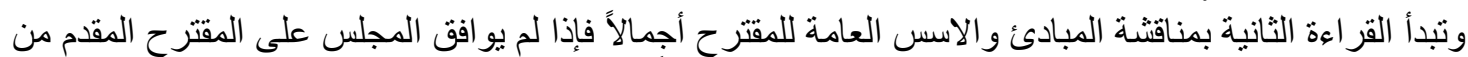

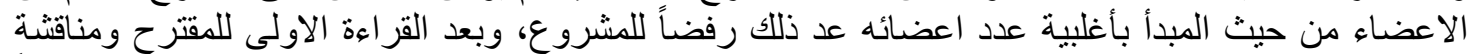

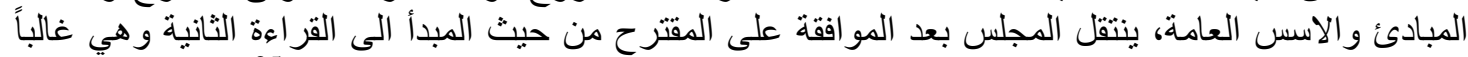

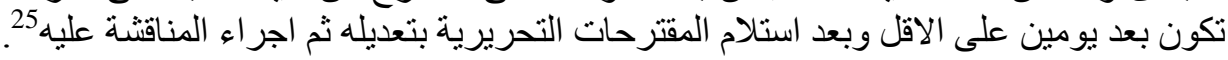

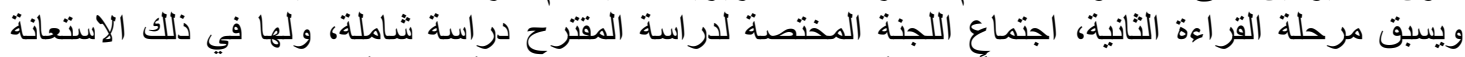

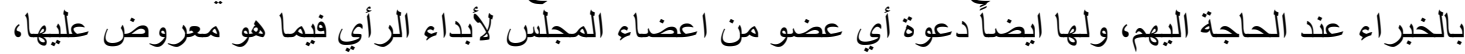

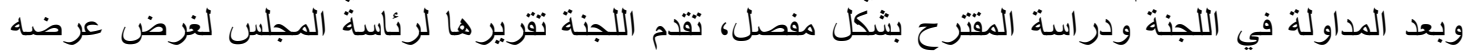

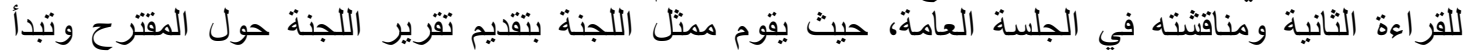

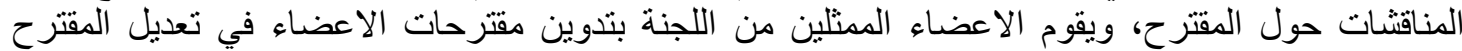
الاصلي. وتعد القر اءة الثانية بمثابة المر اجعة و الدر اسة النهائية للمقتر ح، فبعد الانتهاء من القر اءة الثانية وفي الجلسة العامة

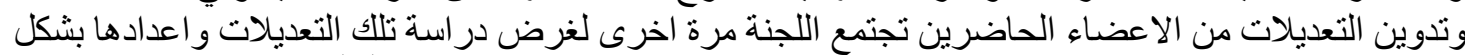

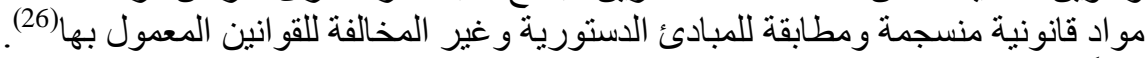

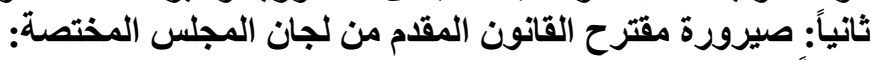

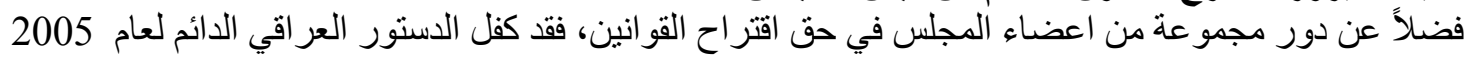

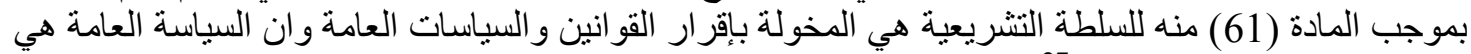

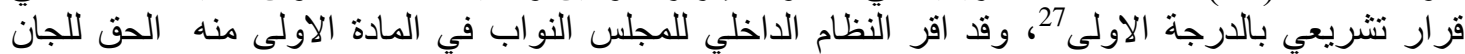

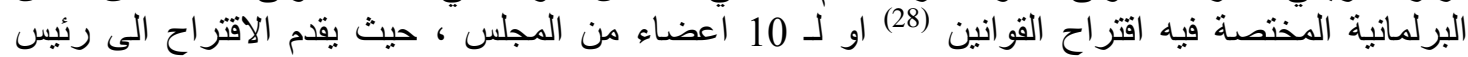

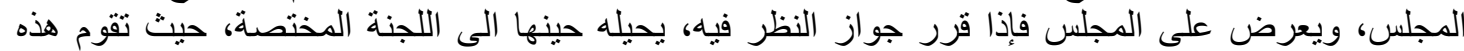
اللجنة بدر اسة المقترح و اعادته الى رئيس الذي بدوره يحيل مقترح القانون الى اللجنة القانونية لمر اجعة صياغته

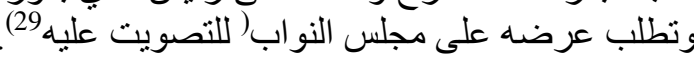

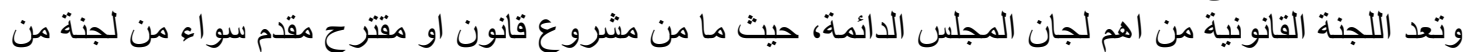

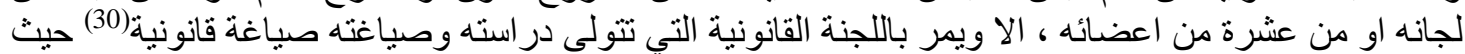

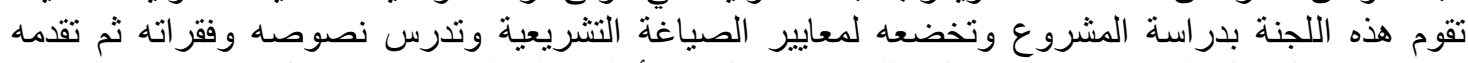

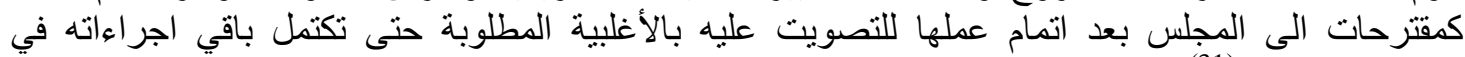

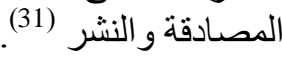




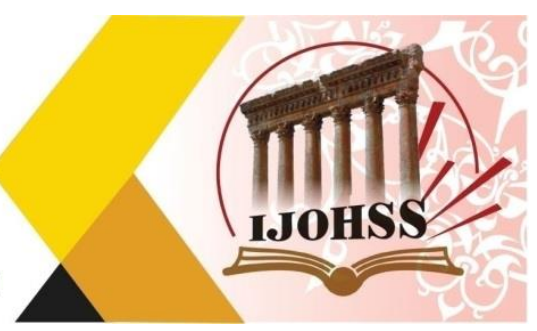

$$
\text { مخطط رقم (2) يوضح هيكلية مجلس النواب العراقي }
$$

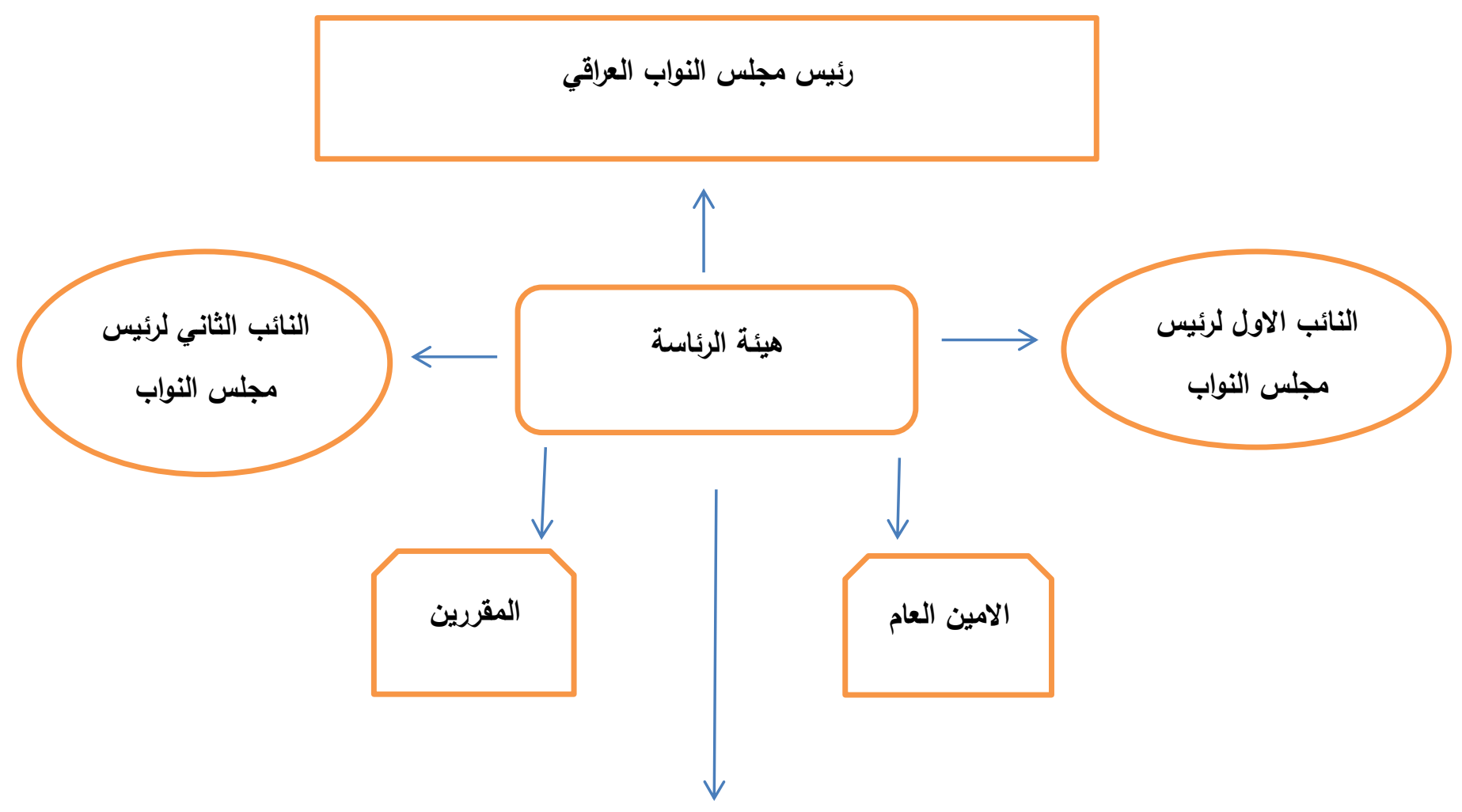

لجان مجلس النواب العراقي

المخطط من اعداد الباحث بالاستناد الى الهيكلية و النظام الداخلي للمجلس النواب العر اقي.

المطلب الثاني: دور اللجان النيابية في صياغة وتصديق مشروعات القوانين:

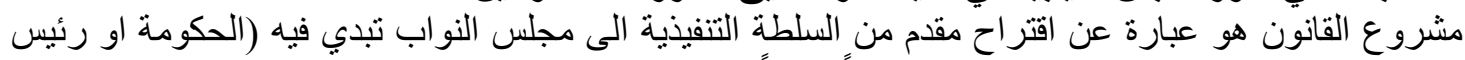

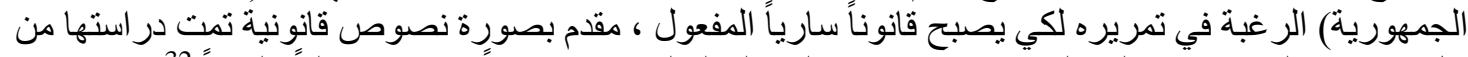

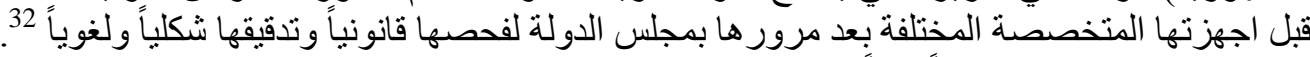

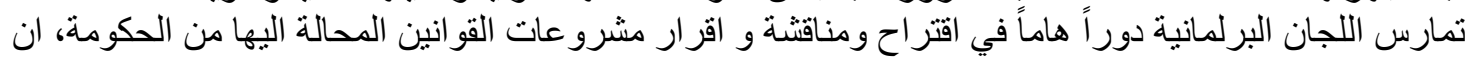

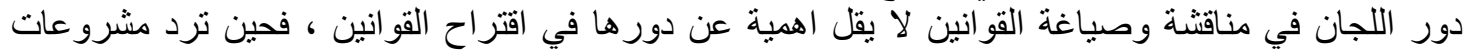

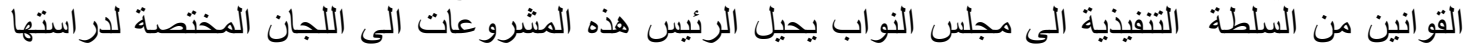


و ابداء الرأي فيها قبل عرضها على المجلس لمناقشتها على ان يجري ذلك بحضور ممثل من الجهة مقدمة

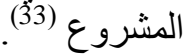

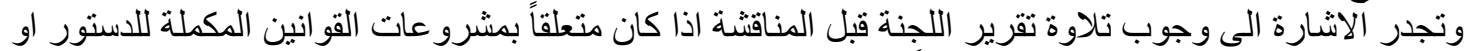

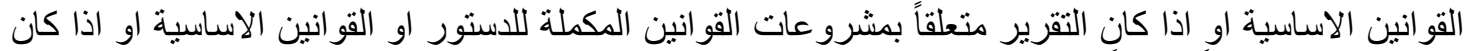

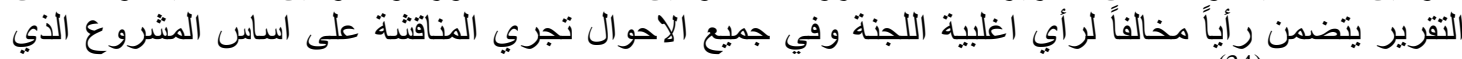
تقدمت به اللجنة (34). مع ملاحظة انه اذا قدم مشروع قانون مرتبط به مشاريع قوانئ النين اخرى محالة الى احدى اللجان، احالة رئيس

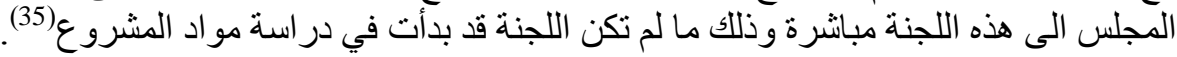

المطلب الثالث: عوامل نجاح اللجان النيابية في العملية التشريعية:

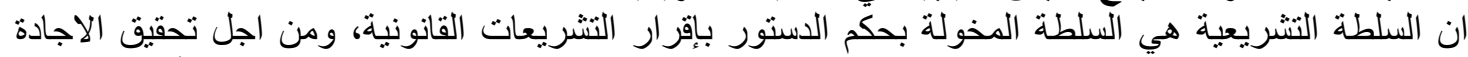

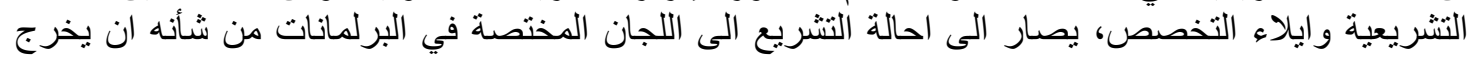

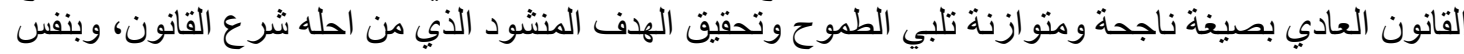

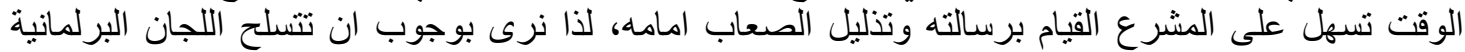

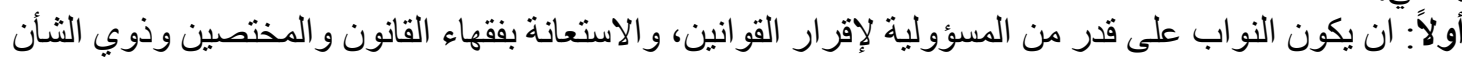

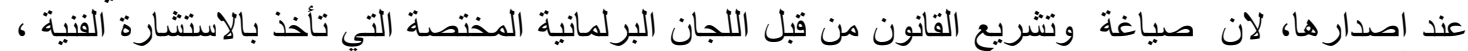

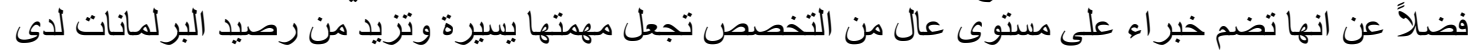

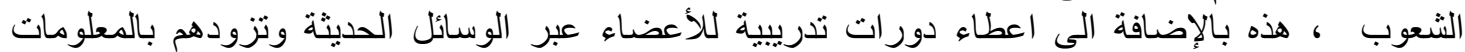

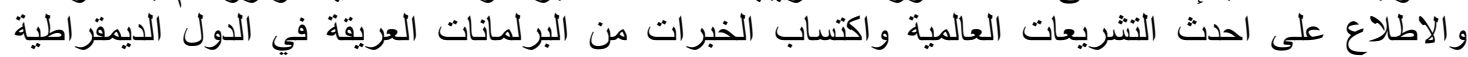

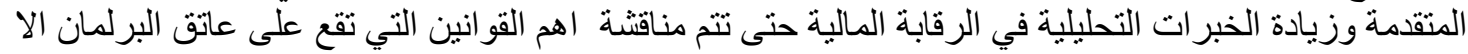

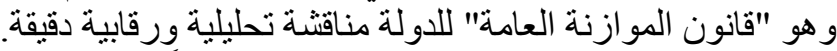

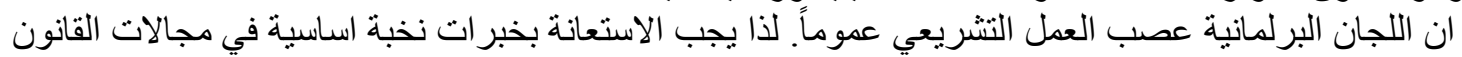

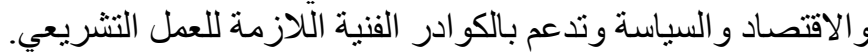

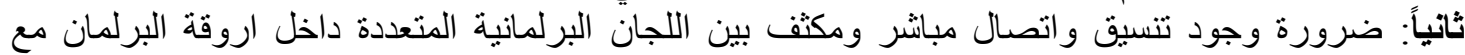

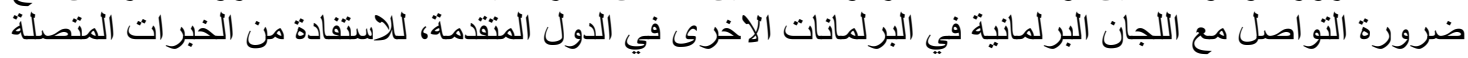

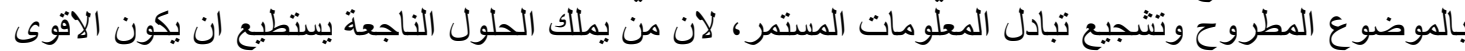
والاجدر على الاقناع و هذا دور اللجان البرلمانية.

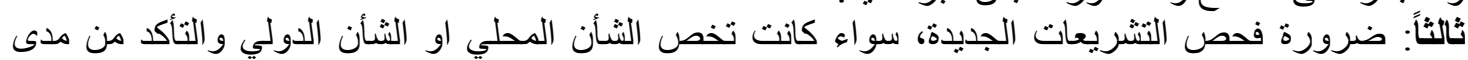

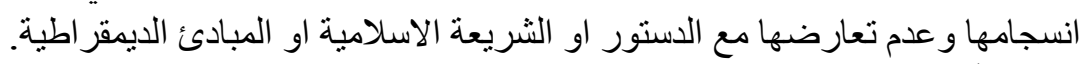

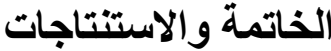

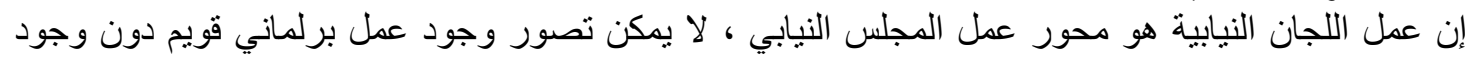

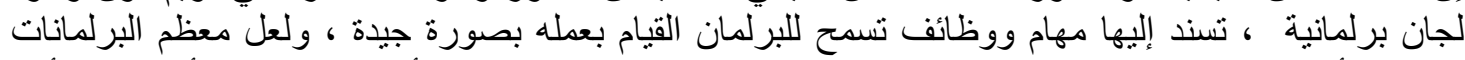

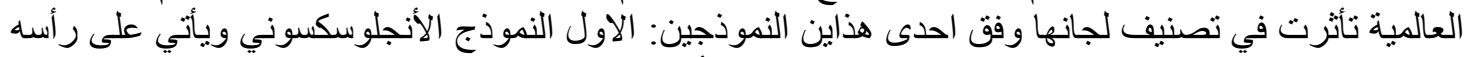

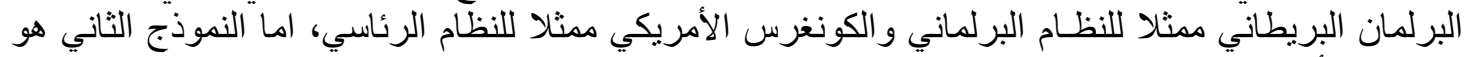

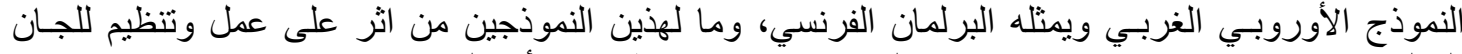

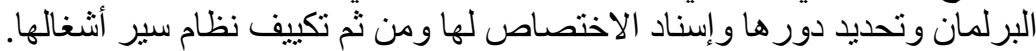

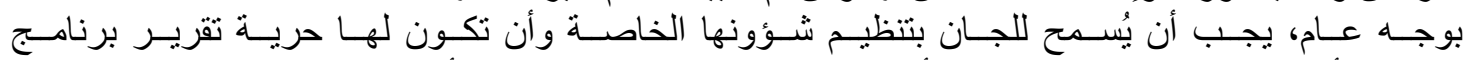

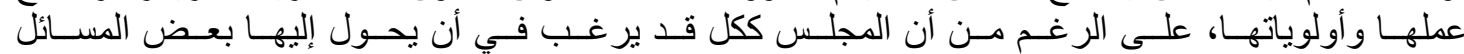

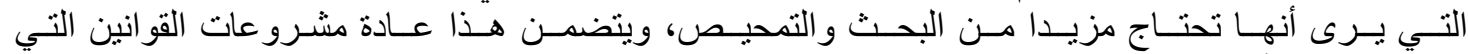

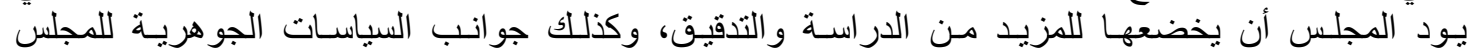

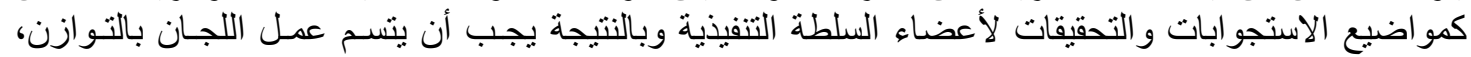




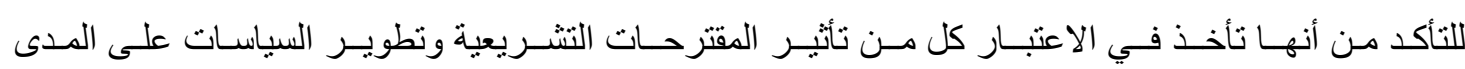
الطويلـ.

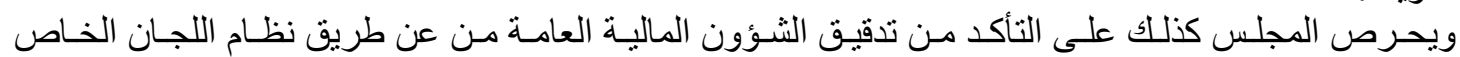

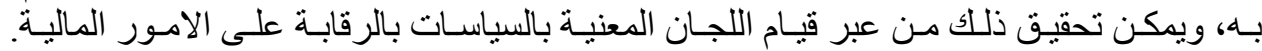

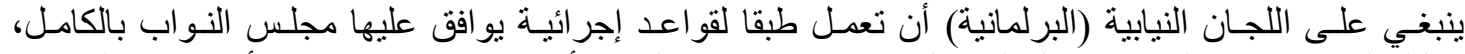

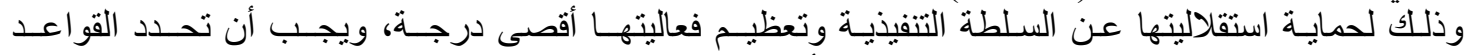

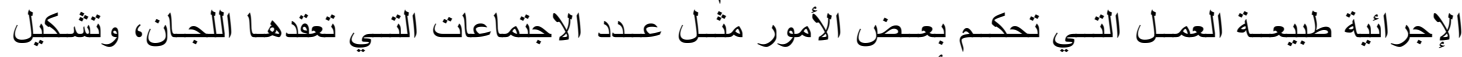

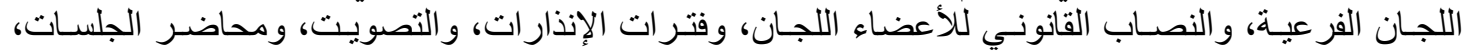

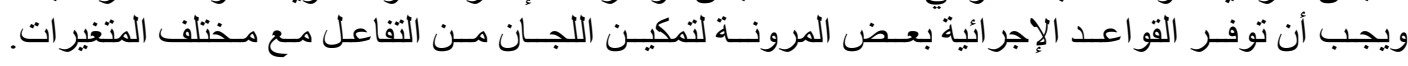

| - الاستنتاجات

تساهم اللجان النيابية في تعزيز قوة وفعالية اداء الحكومات ، كما تؤدي الى تحسين العملية السياسية الديمقر اطية ،

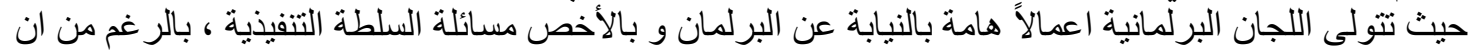

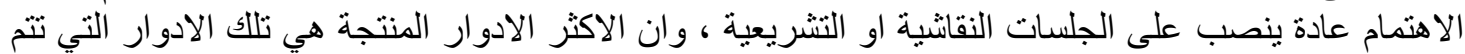

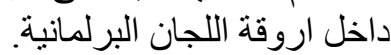

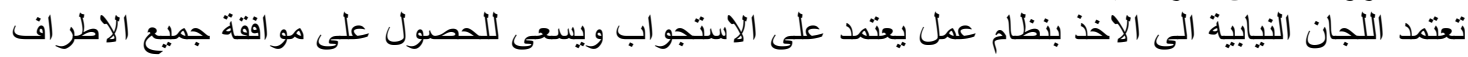

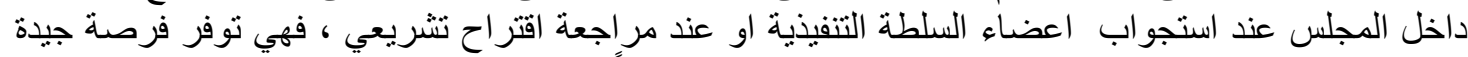

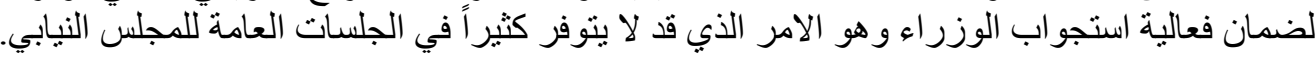

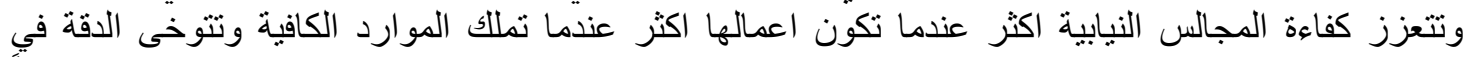

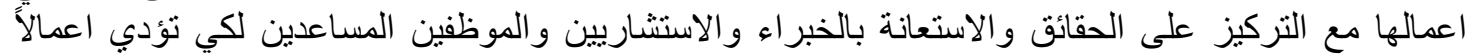

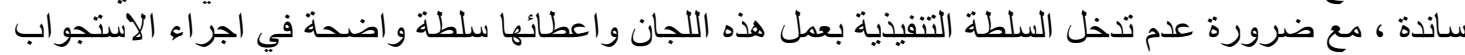

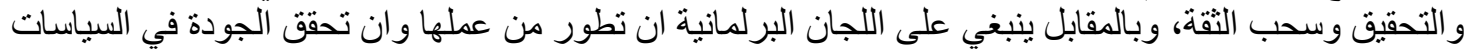

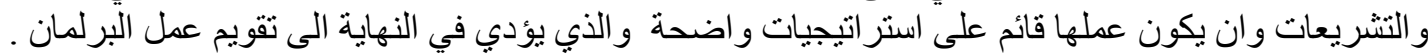

التوصيات

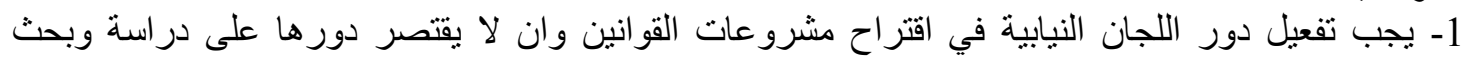

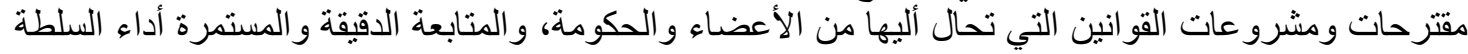
التنفيذية، ومدى تنفيذها للقانون وملائمة للو اقع.

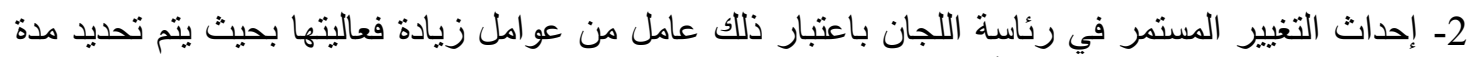

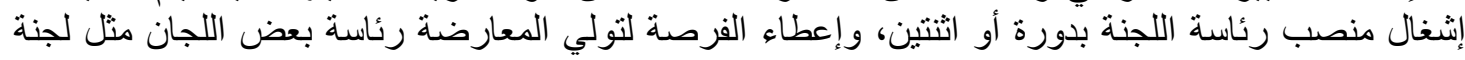
حقوق الإنسان و اللجنة المالية.

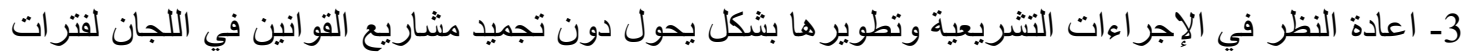

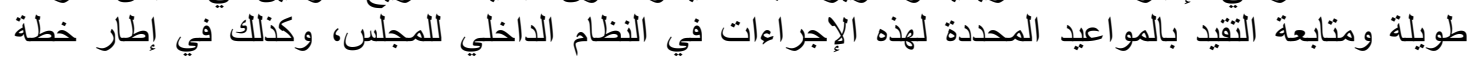
التشريع السنوية للمجلس.

4- تفويض صلاحيات أوسع للجان في متابعتها لمؤسسات السلطة التنفيذية بما يشمل مخاطبتها و استدعاء ممثليها،

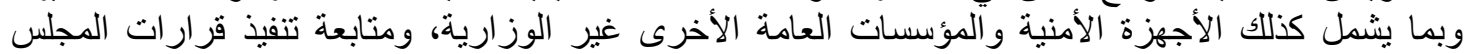
المتخذة بناء على توصياتها.

6- معالجة محدودية العدد في بعض اللجان وإعادة النظر في التشكيلة الحالية للجان بحيث ينم الدمج بين اللجان

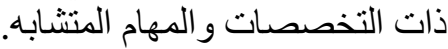


7- لا بد من ابعاد رئاسة هذه اللجان و عضويتها من المحاصصة وان تقوم بدل ذللك على ركن التخصص و الكفاءة لأجل تحقيق الاجادة التشريعية بما يطلبه الوضع الونعاد العام في البلاد.

${ }^{1}$ D.G.Lavroff, Le Droit Constitutionnel de la v ${ }^{\circ}$ Republique, paris, 1995, p $494 .$.

${ }^{2}$ Eric Oliva, Droit Constitutionnel, Edition Dalloz, paris, 1977, p 194.

3 كيف تعمل البرلمانات : العمليات و الاجراءات البرلمانية ، ورقة بحثية صادرة عن مجلس البرلمانات العالمية ، للمزيد ،

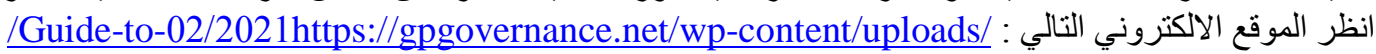
-ARABIC.pdf2Parliaments.-Paper-

(4) دليل سير العمل في جلسات مجلس النواب، اعداد مكتب النائب الاول لرئيس مجلس النواب العر اقي، الدائرة الاعلامية،

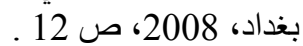
(5)(5رو أحمد حسبو: اللجان البرلمانية دراسة مقارنة، مجلة العلوم الادارية، دار الفيومي، العدد 12، جامعة القاهرة،

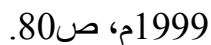

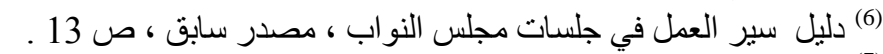

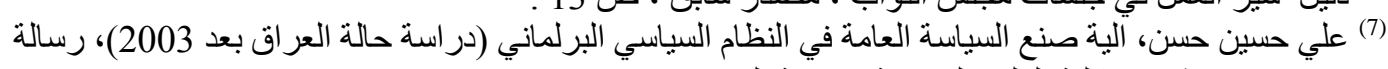

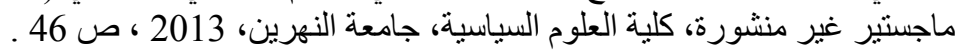

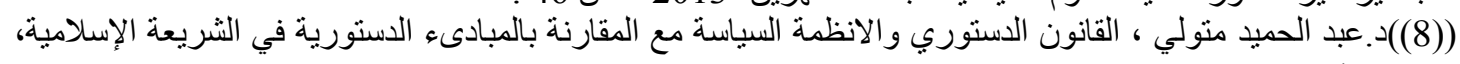

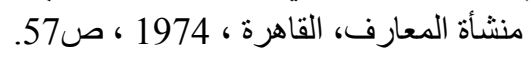

(9)( عامر عايش الجبوري، تكوين اللجان البرلمانية واختصاصها، مجلة الرافدين للحقوق، العدد (25)، كلية الحقوق،

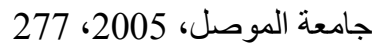

${ }^{(10)}$ Kaarestrom , Parliamentary Committees in European Democracies, the journal of legislative studies. Vol .4.spring 1998, no ,1 .

(11) Kaarestrom, Parliamentary Committees in European Democracies, (ibid.).

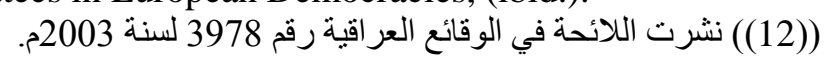

(13)() د. حميد خالد حنون، مبادئ القانون الدستوري ونطوير النظام السياسي في العراق، مكتبة السنهوري، بيروت،

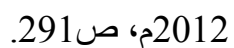

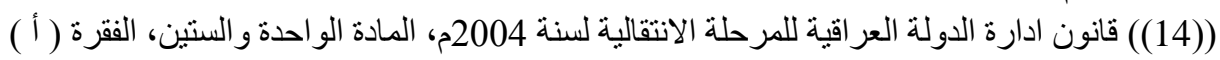

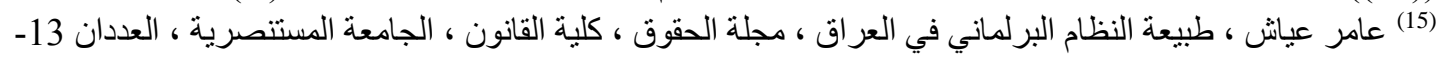

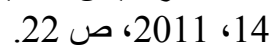

(16)() (16) المادة (128) من النظام الداخلي لمجلس النواب العر اقي.

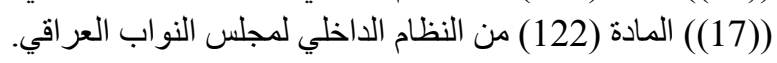

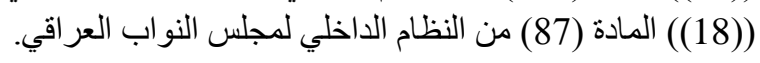

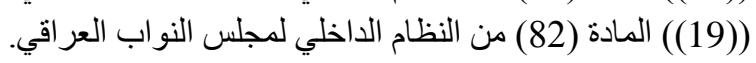

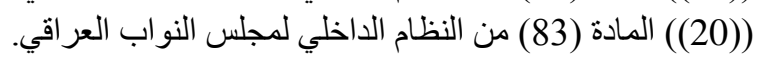

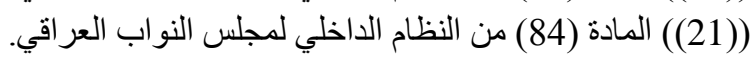

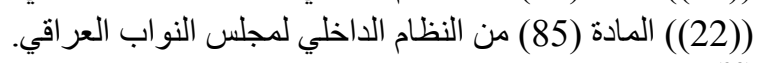

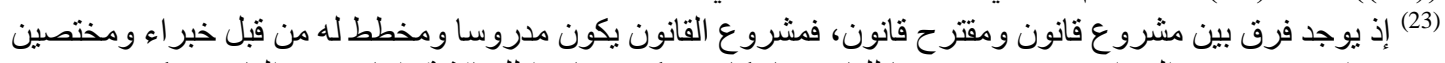

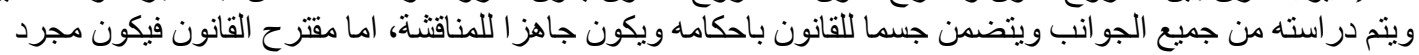

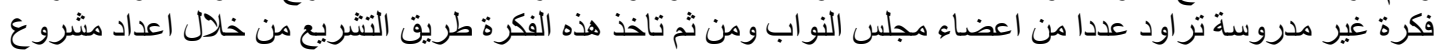

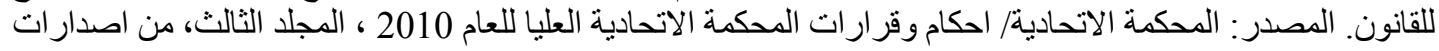


(24) عمار طارق عبد العزيز، المحكمة الاتحادية العليا في الدستور العر اقي، مجلة شؤون عراقية، مركز الدراسات

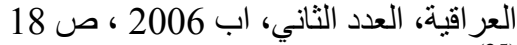

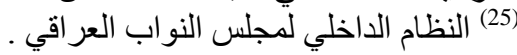

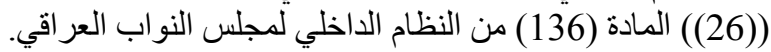

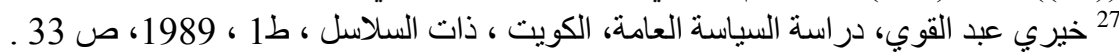
(28)( المادة (60) من دستور جمهورية العراق لعام 2005م النافذ والمادة (1) من النظام الداخلي لمجلس النواب العر اقي. (29)()) المادة (112) من النظام الداخلي لمجلس النواب العراقي.

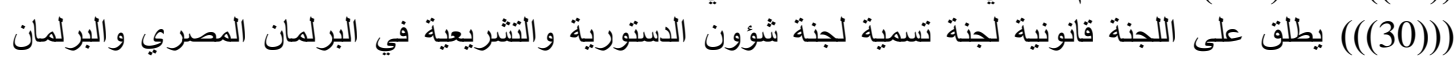

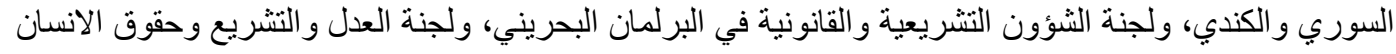

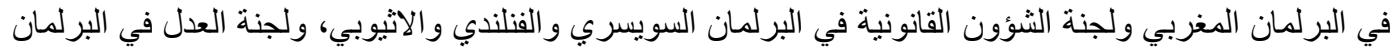
الأسكتلندي. (31)()() صباح جمعة الباوي، اختصاصـات اللجان القانونية في البرلمان المقارنة، مجلس النواب العر اقي، دائرة البحوث،

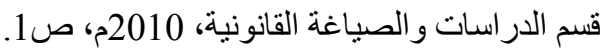

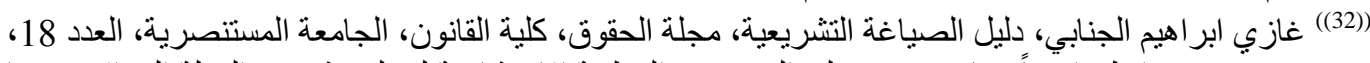

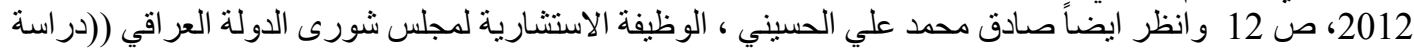

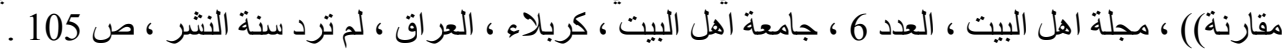

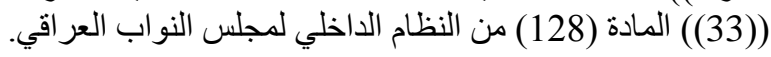

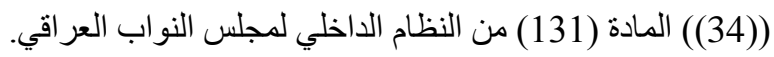
(35)(المادة (123) من النظام الداخلي لمجلس النواب العراقي.

المصادر اولاً: الوثائق والقوانين

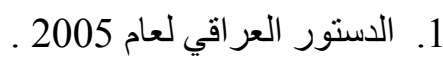

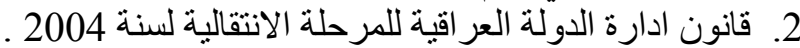

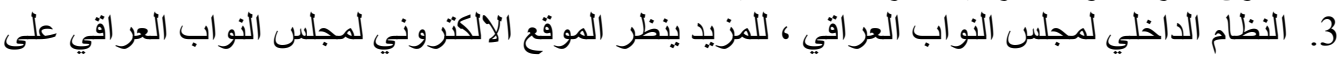
https://ar.parliament.iq الانترنيت على الر ابط التالي : الإن 4. كيف تعمل البرلمانات : العمليات و الاجر اءات البرلمانية ، ورقة بحثية صادرة عن مجلس البرلمانات العالمية العالية https://gpgovernance.net/wpcontent/uploads/02/2021/Guide-to-Parliaments.-Paper-2-ARABIC.pdf

ثانياً : الكتب العربية 1.د. حميد خالد حنون، مبادئ القانون الدستوري ونطوير النظام السياسي في العراق، مكتبة السنهوري، بيروت .2012 2. د.خيري عبد القوي، دراسة السياسة العامة، الكويت ، ذات السلاسل ، ط1 ، 1989.

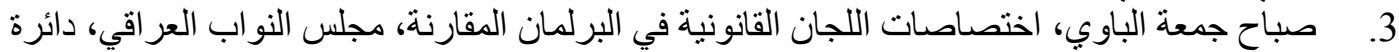
البحوث، قسم الدراسات والصياغة القاني، التيانية، 2010. 


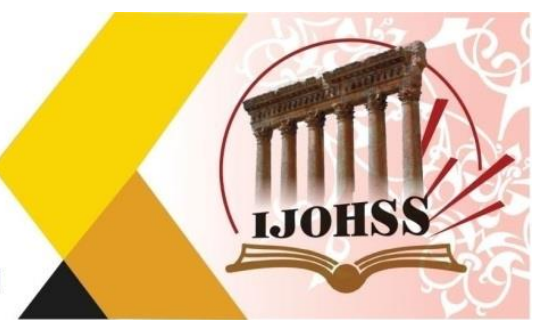

4.د.عبد الحميد متولي ، القانون الدستوري والانظمة السياسة مع المقارنة بالمبادىء الدستورية في الثريعة الإسلامية، منشأة المعارف، القاهرة ، 1974 ـ

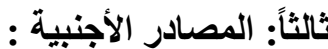

1. D.G.Lavroff, Le Droit Constitutionnel de la v ${ }^{\circ}$ Republique, paris, 1995.

2. Eric Oliva, Droit Constitutionnel, Edition Dalloz, paris, 1977, p 194.

3. Kaarestrom , Parliamentary Committees in European Democracies, the journal of legislative studies. Vol .4.spring 1998

1. رسالة ماجستير غير منشورة، كلية العلوم السياسية، جامعة النهرين، 2013 النيان النياني

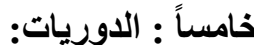

1. دليل سير العمل في جلسات مجلس النواب، اعداد مكتب النائب الاول لرئيس مجلس النواب العر اقي، الدائرة الاعلامية، بغداد، 2008 العمل فيل

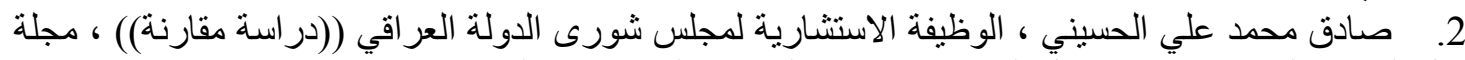

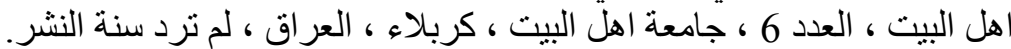
3. 4. عامر عايش الجبوري، تكوين اللجان البرلمانية واختصاصها، مجلة الر افدين للحقوق، العدد (25)، كلية الحقوق، جامعة الموصل،

5. عامر عياش ، طبيعة النظام البرلماني في العراق ، مجلة الحقوق ، كلية القانون ، الجامعة المستنصرية ،

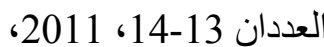

6. عمار طارق عبد العزيز، المحكمة الاتحادية العليا في الدستور العراقي، مجلة شؤون عراقية، مركز

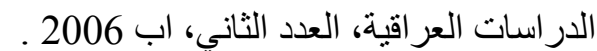

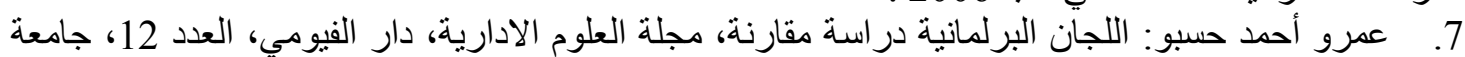

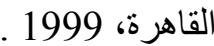

8. غ غازي ابر اهيم الجنابي، دليل الصياغة التشريعية، مجلة الحقوق، كلية القانون، الجامعة المستتصرية، العدد . 2012 ، 18

9. المحكمة الاتحادية/ احكام وقرارات المحكمة الاتحادية العليا للعام 2010 ، المجلد الثالث، من اصدارات جمعية القضاء العر اقي. 